\title{
Rapid detection of the hypoxia-regulated CA-IX and NDRG1 gene expression in different glioblastoma cells in vitro
}

\author{
HARUN M. SAID ${ }^{1 *}$, BUELENT POLAT ${ }^{1 *}$, ADRIAN STAAB $^{1}$, CARSTEN HAGEMANN $^{2}$, SUSANNE STEIN $^{3}$, \\ MICHAEL FLENTJE $^{1}$, MATHIAS THEOBALD ${ }^{3}$, ASTRID KATZER ${ }^{1}$ and DIRK VORDERMARK ${ }^{1}$
}

\author{
Departments of ${ }^{1}$ Radiation Oncology, ${ }^{2}$ Neurosurgery, University of Wuerzburg; ${ }^{3}$ Department of \\ Hematology and Oncology Johannes Gutenberg University III, Medical School, 55101 Mainz, Germany
}

Received January 18, 2008; Accepted April 7, 2008

DOI: 10.3892/or_00000023

\begin{abstract}
Hypoxia-inducible factor-1 (HIF-1) is a key regulator of tumor cell hypoxia. It regulates the expression of several genes related to oxygen homeostasis in response to hypoxic stress. Carbonic anhydrase IX (Ca-IX) has been found to be a stable marker of acute or chronic hypoxia. N-Myc down-regulated gene 1 (NDRG1) has been shown to possess more specific characteristics for clinical analysis and identification purposes. HIF-1 activates gene expression of the two genes and promotes tumor cell survival under hypoxic conditions. Herein, we modified a flow cytometry protocol to separate NDRG1- and CA-IX-negative and -positive cells in vitro to sort chronically hypoxic cells from glioblastoma tumors. The FITC-anti-CA-IX fluorescence differed between positive and negative cells by a factor of 60-160 in U373, U87-MG, U251 and GaMG, respectively. A clear effect of the $\mathrm{O}_{2}$ concentration on CA-IX expression was visible in GaMG and U251 cell lines whereas U373 showed a less differentiated pattern. NDRG1 expression was present in U373, U251 and GaMG with the lowest expression rate in GaMG. It was stable over $48 \mathrm{~h}$ of reoxygenation after $24 \mathrm{~h}$ of extreme hypoxia $\left(0.1 \% \mathrm{O}_{2}\right)$. During reoxygenation NDRG1 was relatively stable in the four tumor cell lines with the lowest expression in GaMG. An oxygen- and time-dependent elevation of nuclear HIF-1 $\alpha$ binding on HRE was displayed. FACS analysis of CA-IX and NDRG1 expression may be a new approach to determining the hypoxic state of tumor cells. However, an extensive analysis of other hypoxia-regulated
\end{abstract}

Correspondence to: Dr Harun M. Said, Department of Radiation Oncology, University of Würzburg, Josef-Schneider-Str. 11, 97080 Würzburg, Germany

E-mail: said_h@klinik.uni-wuerzburg.de

${ }^{*}$ Contributed equally

Key words: tumor hypoxia, hypoxia, reoxygenation, oxygen, radiotherapy, carbonic anhydrase-IX, N-Myc down-regulated gene 1, hypoxia-inducible factor- $1 \alpha$ genes in different tumors is required to identify additional markers for the detection of the oxygenation state in human tumors in order to tailor effective tumor-specific therapeutic strategies.

\section{Introduction}

Glioblastoma multiforme (GBM) are highly invasive brain tumors (1). The transcription factor hypoxia-inducible factor-1 (HIF-1) is a key regulator of tumor cell adaptation and survival under hypoxic conditions (2). It regulates the expression of several genes related to oxygen homeostasis in response to hypoxic stress (3). Human glioblastoma multiforme cells vary in their ability to survive under hypoxic conditions. Tumor hypoxia is a complex entity which is a function of oxygen supply and demand. A shift toward anaerobic metabolism would decrease oxygen consumption rates, which may lead to improvement in tumor oxygenation (4). Under oxygen-limiting conditions, hypoxia-tolerant cells decrease their oxygen consumption rate whereas hypoxia-sensitive cells continue to consume oxygen at a relatively steady rate until the oxygen supply becomes exhausted (5). HIF-1 activates gene expression and promotes tumor cell survival under hypoxic conditions (reduced oxygen tension) (6). In solid tumors, the degree of tumor hypoxia correlates with advanced disease stages and poor prognosis (7). Clinical studies indicate that overexpression of HIF-1 $\alpha$ is a negative indicator for tumor treatment outcome $(8,9)$. Therefore, it is important to establish genetic markers to detect conditions of tumor tissue oxygenation.

The CA-IX protein is a transmembrane $\mathrm{N}$-glycosylated isoenzyme localized at the cell surface in the form of trimers composed of monomeric subunits of $58 / 54 \mathrm{kDa}$. It is a stable marker of current or previous chronic hypoxia, influenced by non-hypoxic stimuli (10). Carbonic anhydrase IX (CA-IX) is regarded as a surrogate marker of tumor hypoxia in human malignant glioma (11-13). NDRG1 has been shown to possess more specific characteristics for clinical analysis and identification purposes. NDRG1 is a member of the N-myc downregulated gene (NDRG) family. NDRG1 (also known as Drg 1, RTP , Rit42, PROXY-1 and Cap43) was identified as a gene up-regulated during cellular differentiation (14-18). It is induced by hypoxia $(19,20)$. Due to its specific hypoxia-related expression in human GBM, NDRG1 represents a potential diagnostic marker for severe brain tumor types. Together with 
other transcription factors such as Egr-1 $(23,24)$, HIF-1 is also involved in the transcriptional regulation of the NDRG1 gene $(21,22)$.

It is well known that tumor hypoxia is associated with adverse outcome in many malignancies. Tumor oxygenation is directly measured using microelectrodes or $\mathrm{RuO}_{2}$ microprobes. However, these techniques possess an invasive nature, restricting their use to accessible tumors (25). Additional diagnostic tumor markers whose expression is induced by the hypoxic microenvironment of the tumor are necessary for definite advanced characterisation of a tumor according to its oxygenation status. This analysis should be performed prior to designing and executing a suitable anti-tumor therapy approach. Different rapid methods such as FACS, Western blotting and/or ELISA function for this purpose and may be applied prior to treatment. However, they are dependent on tumor type and the ability to obtain tumor specimens. Herein, we use FACS analysis to separate CA-IX and NDRG1 expressing from non-expressing cells, thereby determining whether cells were grown under hypoxic conditions.

\section{Materials and methods}

Cell and culture conditions and hypoxia treatment. Earlypassage U373, U251 and U87-MG human malignant glioblastoma cell lines from the American Type Culture Collection (ATCC, Rockville, MD, USA) and GaMG, a cell line established from a patient with glioblastoma multiforme (Gade Institut of the University of Bergen, Norway) (26), were grown on glass petri dishes in Dulbecco's modified Eagle's medium (DMEM) supplemented with $10 \%$ fetal bovine serum (FBS), non-essential amino acids, penicillin (100 IU/ml)/ streptomycin $(100 \mu \mathrm{g} / \mathrm{ml})$ and $2 \mathrm{mM} \mathrm{L-glutamine.} \mathrm{Cells} \mathrm{were}$ exposed to $0.1 \% \mathrm{O}_{2}$ for 1,6 or $24 \mathrm{~h}$ in a Ruskinn Invivo hypoxic workstation (Cincinnati, OH, USA) as previously described (27) for in vitro hypoxia. For the reoxygenation experiments, dishes were returned to the incubator following 24 h hypoxia treatment.

Preparation of cell lysates and immunoblotting. Tumor cell lysates were prepared with $0.1 \mathrm{ml}$ RIPA buffer (1X TBS, $1 \%$ Nonidet P-40 (Amresco, Vienna, Austria), 0.5\% sodium deoxycholate, $0.1 \%$ SDS, protease inhibitors pepstatin A $(1.4 \mu \mathrm{M})$, aprotinin $(0.15 \mu \mathrm{M})$, leupeptin $(2.3 \mu \mathrm{M})$ and $100 \mu \mathrm{M}$ PMSF (all from Sigma, St. Louis, MO, USA). To inhibit protein dephosphorylation, phosphatase inhibitor mix (Sigma) was added. Using a syringe fitted with a 21-gauge needle to shear DNA, the lysates were transferred to a prechilled microcentrifuge tube, followed by 30 min incubation on ice. The cell lysate clearance was by centrifugation at $15,000 \mathrm{x} \mathrm{g}$ for $12 \mathrm{~min}$ at $4^{\circ} \mathrm{C}$. Whole-cell lysates $(20 \mu \mathrm{g})$ were separated on $8 \%$ polyacrylamide SDS gel. Electrophoresis was then transferred to a $0.45 \mu \mathrm{m}$ nitrocellulose membrane (Protran BA 85, Schleicher \& Schuell, Dassel, Germany). Non-specific binding was blocked by $5 \%$ non-fat milk powder in TBS overnight at $4^{\circ} \mathrm{C}$ followed by incubation with the NDRG1 primary antibody (ab8448, Abcam, Cambridge, UK), diluted 1:1000 in 2.5\% non-fat milk powder in TBS for $1 \mathrm{~h}$ at room temperature. Blots were washed twice in $\mathrm{TBS} / 0.05 \%$ Tween-20 (Bio-Rad, Munich, Germany) and subsequently three times in TBS for 5-10 min, each. The secondary antibody goat anti-rabbit-HRP (stock solution: $400 \mu \mathrm{g} / \mathrm{ml}$, DakoCytomation, Denmark) was incubated at a dilution of 1:2000 for one additional hour at room temperature followed by five washing steps as described above. Detection of the bound antibodies was accomplished by membrane development with ECL plus a Western blotting detection system (Amersham Biosciences, Cambridge, UK) for $5 \mathrm{~min}$ with subsequent development of the Hyperfilm ECL (Amersham) used for detection purposes.

Preparation of the nuclear extracts. Cells $/ \mathrm{ml}\left(5 \times 10^{7}\right)$ were scratched from petri dishes by adding $10 \mathrm{ml}$ phosphate buffered saline (PBS) to the cellular film according to previous protocols (28) with minor modifications. A cell line pellet was obtained by centrifugation (Beckman CS-6R) for $4 \mathrm{~min}$ at $800 \mathrm{rpm}$. After two washing steps with PBS, cells were resuspended in $1 \mathrm{ml} \mathrm{PBS}$, transferred into a $1.5 \mathrm{ml}$ tube and centrifuged at $4^{\circ} \mathrm{C}$ for $45 \mathrm{sec}$ at $14,000 \mathrm{rpm}$. The cell pellet was re-suspended in $400 \mu 1$ ice-cold buffer A [10 mM Hepes pH 7.9, 10 mM KCl, 0.1 mM EDTA, 0.1 mM EGTA, 1 mM PMSF, $10 \mu 1$ complete protease inhibitor cocktail (Roche) and $1 \mathrm{mM}$ DTT] and incubated on ice for $15 \mathrm{~min}$. The cells were lysed by adding $25 \mu 1$ of $10 \%$ NP-40 and homogenized with 10 strokes in a Dounce homogenizer at $4{ }^{\circ} \mathrm{C}$ followed by centrifugation for $1 \mathrm{~min}$ at $14,000 \mathrm{rpm}$ for nuclei sedimentation. Supernatants were carefully removed and regarded as cytoplasmic fractions. Nuclear proteins were extracted by adding $50 \mu \mathrm{l}$ of buffer $\mathrm{C}$ [20 mM Hepes, $\mathrm{pH} 7.9,0.4 \mathrm{M} \mathrm{NaCl}$, $1 \mathrm{mM}$ EDTA, $1 \mathrm{mM}$ EGTA, $1 \mathrm{mM}$ PMSF and $0.1 \mu 1$ protease inhibitor cocktail (Roche)] and extensively shaking the tubes for $20 \mathrm{~min}$ at $4^{\circ} \mathrm{C}$ in a tube shaker followed by centrifugation at $14,000 \mathrm{rpm}$ and $4^{\circ} \mathrm{C}$ for $5 \mathrm{~min}$. The supernatant was removed and stored in aliquots at $-80^{\circ} \mathrm{C}$. All steps were performed on ice.

$H I F-1 \alpha$ binding assay. HIF- $1 \alpha$ transcriptional activation was detected by utilizing the ELISA-based TransBinding kit (TransBinding HIF assay kit, EK1020-PA, Biocat, Heidelberg, Germany) according to the manufacturer's instructions. The glioblastoma cell lines U373, U251, U87-MG and GaMG were cultured under various aeration periods of extreme hypoxia exposure $\left(0.1 \% \mathrm{O}_{2}\right)$, and under oxygenized conditions. Nuclear extracts $(20 \mu \mathrm{g})$ were obtained from the cells. The binding capacity to the hypoxia responsive element (HRE) was analysed for each situation in triplicate per experimental set.

Determination of NDRG1 and CA-IX expression via FACS analysis. NDRG1 and CA-IX expression was determined by flow cytofluorometry employing the FACSCalibur ${ }^{\mathrm{TM}}$ flow cytofluorometer (Becton-Dickinson, Heidelberg, Germany, low-power argon laser excitation at $488 \mathrm{~nm}$ ) and CellQuest Pro $^{\text {TM }}$ software as cell-associated fluorescence. For each analysis, 10.000 gated events were collected.

The experimental basis was previously described (29-33) and was successfully applied after modification. U251, U373, U87-MG and GaMG cells were kept under aerobic as well as hypoxic $\left(0.1 \% \mathrm{O}_{2}\right)$ conditions for 1,6 and $24 \mathrm{~h}$. Reoxygenation after $24 \mathrm{~h}$ of hypoxia was for $24 \mathrm{~h}$. 


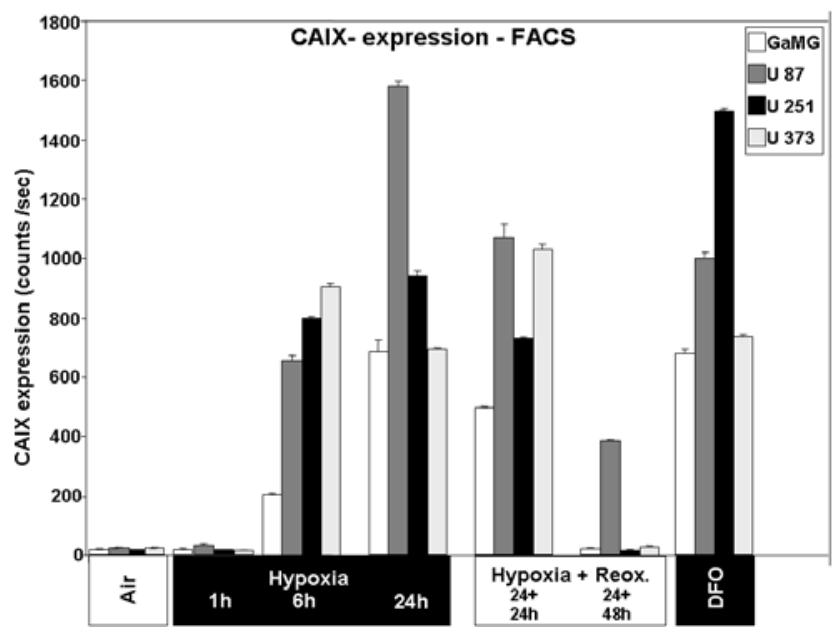

Figure 1. Representative carbonic anhydrase IX (CA-IX) flow cytometry with suspensions of known aerobic and hypoxic cell populations $\left(0.1 \% \mathrm{O}_{2}\right.$, 1, 6 and $24 \mathrm{~h}$ ). Suspensions of the glioblastoma cell lines U87-MG, U251, U373 and GaMG were incubated with the anti-CA-IX antibody M75 and a fluorescein-isothiocyanate (FITC)-conjugated secondary antibody. In U87MG the mean fluorescence intensity of CA-IX-negative and -positive cells differed by a factor of $\sim 160$. In U251 this factor was $\sim 120$ followed by 80 and 60 for U373 and GaMG, respectively. We assume that some hypoxic cells remained CA-IX negative. A high grade of CA-IX expression was still visible upon reoxygenation.

Densitometric evaluation of Western blots and the statistical analysis of measurements. Protein expression signal strengths on Western blots were determined with 1D Kodak Image analysis software. The signals were measured in Kodak light units (KLU) and divided by the corresponding signals of the loading controls $\beta$-tubulin and $\beta$-actin, as previously described (27,30-33). The relative changes in protein expression resulting from submission to hypoxic conditions, or hypoxic conditions with subsequent reoxygenation were analysed in relation to the $24 \mathrm{~h}$ normoxic value. Three to four individual experiments were always performed. The Mann-Whitney U test for independent samples was used to analyse these data. The Student's t-test for unpaired samples was used to analyse overall cell numbers. In the two tests $\mathrm{p} \leq 0.05$ was considered to be statistically significant. All tests were carried out using the statistical package SPSS, release 12.0.1 for Windows (SPSS Inc., Chicago, IL, USA).

\section{Results}

Determination of CA-IX and NDRG1 in human glioblastoma in vitro by FACScan analysis. The basic FACScan protocol has been modified by testing different modes of single-cell suspension preparation, different concentrations of primary antibody and different secondary antibodies at various concentrations. The protocol described herein resulted in the largest spectrum between CA-IX- and NDRG1-negative and -positive cell populations, respectively, and the lowest non-specific staining during flow cytometry.

For CA-IX the FITC fluorescence differed between positive and negative cells by a factor of 60-160 in U373, U87-MG, U251 and GaMG, respectively (Fig. 1). The FITCanti-NDRG1 fluorescence differed between positive and

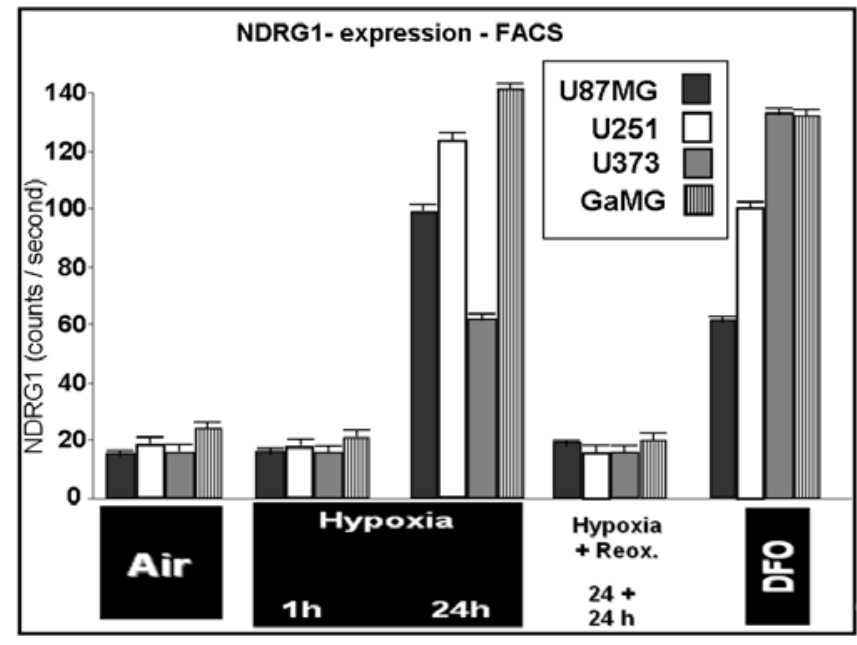

Figure 2. NDRG1 flow cytometry experiment with suspensions of known aerobic and hypoxic cell populations $\left(0.1 \% \mathrm{O}_{2}, 1,6\right.$ and $\left.24 \mathrm{~h}\right)$. Suspensions of the glioblastoma cell lines U87-MG, U251, U373 and GaMG were incubated with the anti-CA-IX antibody M75 and a fluorescein-isothiocyanate (FITC)conjugated secondary antibody. In GaMG the mean fluorescence intensity of NDRG1-negative and -positive cells differed by a factor of $~ 70$. In U251, this factor was $\sim 60$ followed by 35 and 60 for U87-MG and U373, respectively. We assume that some hypoxic cells remained CA-IX negative.

negative cells by a factor of 35-70 in U373, U87-MG, U251 and GaMG, respectively (Fig. 2). In our laboratory, the use of non-enzymatic preparation of cell suspensions was important for high-FITC fluorescence in the two cases.

Intracellular CA-IX protein levels in response to extreme in vitro hypoxia. A clear effect of the $\mathrm{O}_{2}$ concentration on CA-IX expression was visible in GaMG and U251 cell lines by Western blotting (Fig. 3). U373 showed a less differentiated pattern and even severe hypoxia $\left(0.1 \% \mathrm{O}_{2}\right)$ did not produce a detectable increase of CA-IX protein in U87-MG cells (Fig. 3).

NDRG1 protein expression in response to extreme in vitro hypoxia. NDRG1 expression was detectable in U373, U251 and GaMG cells, concomitant with a decrease of the $\mathrm{O}_{2}$ concentration in the tumor environment (Fig. 4). The lowest expression rate was visible in GaMG. NDRG1 expression was stable over $48 \mathrm{~h}$ of reoxygenation after $24 \mathrm{~h}$ of hypoxia. During reoxygenation NDRG1 was relatively stable in the 4 tumor cell lines with the lowest expression in GaMG. Under extreme hypoxic conditions, a high expression rate of NDRG1 was displayed, with a comparatively high expression rate during reoxygenation. GaMG and U373 cells increased the NDRG1 expression after $24 \mathrm{~h}$ at $0.1 \% \mathrm{O}_{2}$, as shown in the Western blots (Fig. 4) with a weak stability over $48 \mathrm{~h}$ of reoxygenation after $24 \mathrm{~h}$ of hypoxia.

Examination of HIF-1a protein binding to the HRE element from human glioblastoma in response to extreme in vitro hypoxia using ELISA. The oxygen- and time-dependent elevation of nuclear HIF-1 $\alpha$ binding to the HRE of CA-IX and NDRG1, respectively, is shown in Fig. 5. A relative stability of Hif- $1 \alpha$ binding upon reoxygenation for 24 and $48 \mathrm{~h}$, 
A

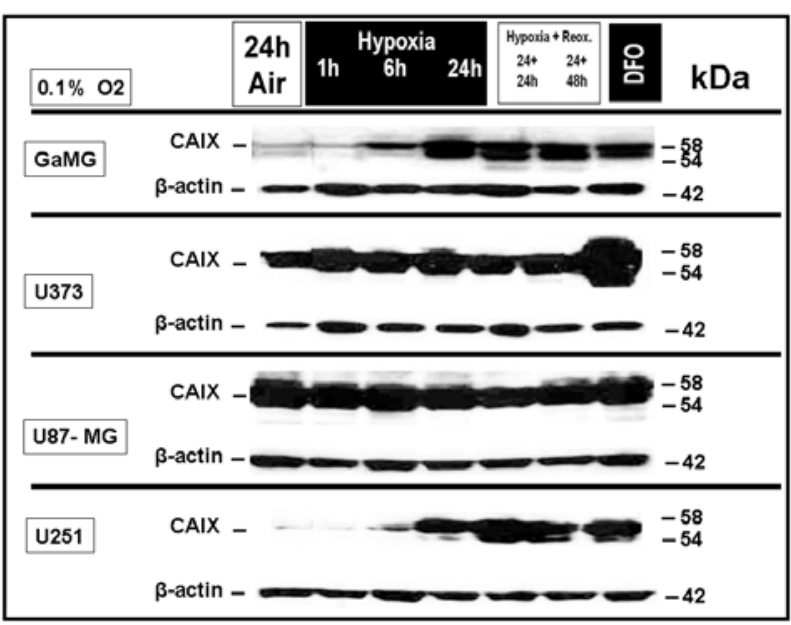

B

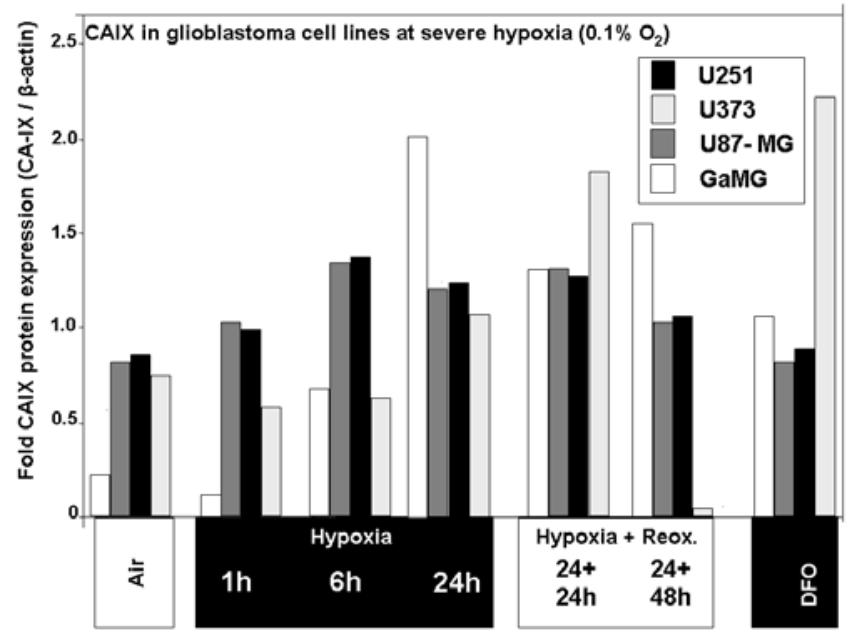

Figure 3. (A) Comparative Western blotting of CA-IX protein expression in whole-cell lysates of the human malignant glioma cell lines U373 and GaMG under in vitro hypoxia and after reoxygenation. (B) Densitometric quantification of CA-IX protein expression.

A

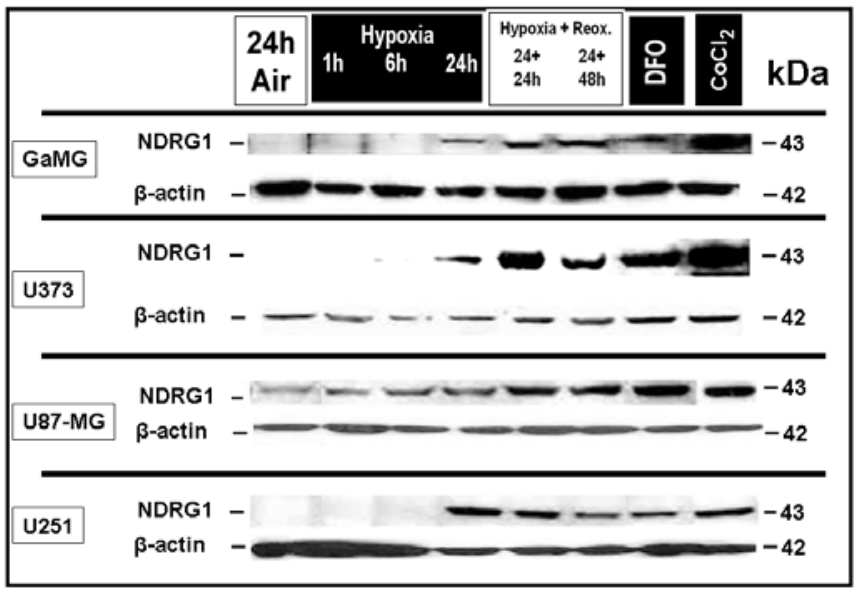

B

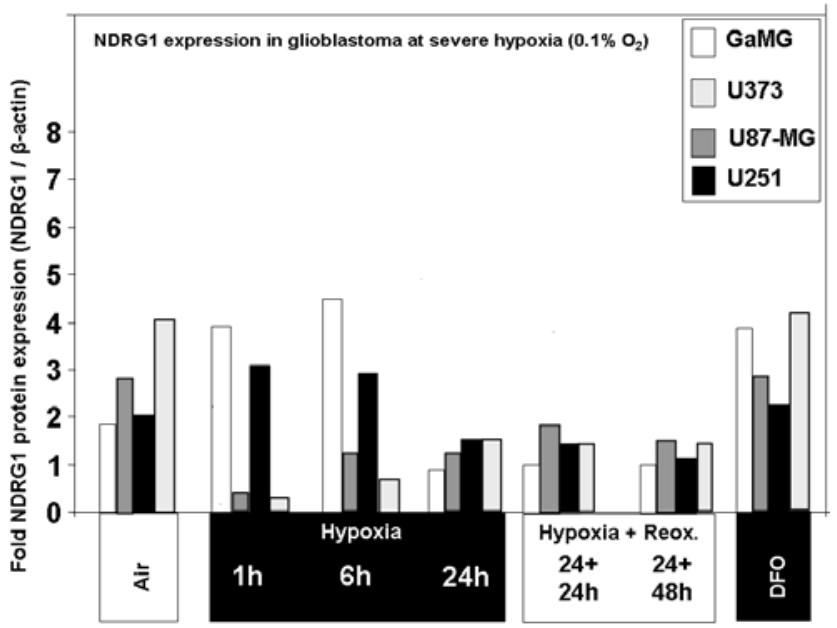

Figure 4. (A) Comparative Western blotting of NDRG1 protein expression in whole-cell lysates of human malignant glioma cell lines under in vitro hypoxia and after reoxygenation. (B) Densitometric evaluation of NDRG1 protein expression in whole-cell lysates under in vitro hypoxia and after reoxygenation.

respectively, after $24 \mathrm{~h}$ hypoxia was observed (Fig. 5). The strongest binding capacity was in U87-MG, followed by GaMG and U373. The weakest HRE binding occurred in U251 cells, reflecting the lowest level of activated nuclear HIF- $1 \alpha$ in this cell line under the conditions examined. Nuclear extracts from glioblastoma cells treated with $100 \mu \mathrm{M}$ DFO and $50 \mu \mathrm{M} \mathrm{CoCl}_{2}$ served as positive controls.

HIF-1 a protein expression in response to extreme in vitro hypoxia. Severe hypoxia conditions $\left(0.1 \% \mathrm{O}_{2}\right)$ resulted in an early increase of HIF-1 $\alpha$ protein expression after $1 \mathrm{~h}$, which was most prominent in U251 and GaMG cells but absent in U87-MG (Fig. 6) due to a high normoxic expression. HIF-1 $\alpha$ protein expression decreased but did not disappear during $24 \mathrm{~h}$ of reoxygenation in $\mathrm{U} 251$, U373 and GaMG, but it nearly disappeared after $48 \mathrm{~h}$ of reoxygenation in these cells (Fig. 6).

\section{Discussion}

Low oxygen tension appears to be a clinically relevant feature of the tumor microenvironment (29). Tumor hypoxia is present in malignant glioma and may represent an independent prognostic factor and an important mechanism for resistance to treatments such as radio- or chemotherapy $(31,34-36)$.

It has been shown that human glioblastoma tissue display resistance to radiation due to an increased activation of the DNA damage checkpoint (37).

Hypoxia-tolerant human glioma cells reduce their oxygen consumption rate in response to oxygen deficit, a defense mechanism that contributes to survival under moderate hypoxic conditions (38). Overcoming the metabolic restrictions of hypoxia may allow for the progression of lower-grade tumors to glioblastoma multiforme (39). 


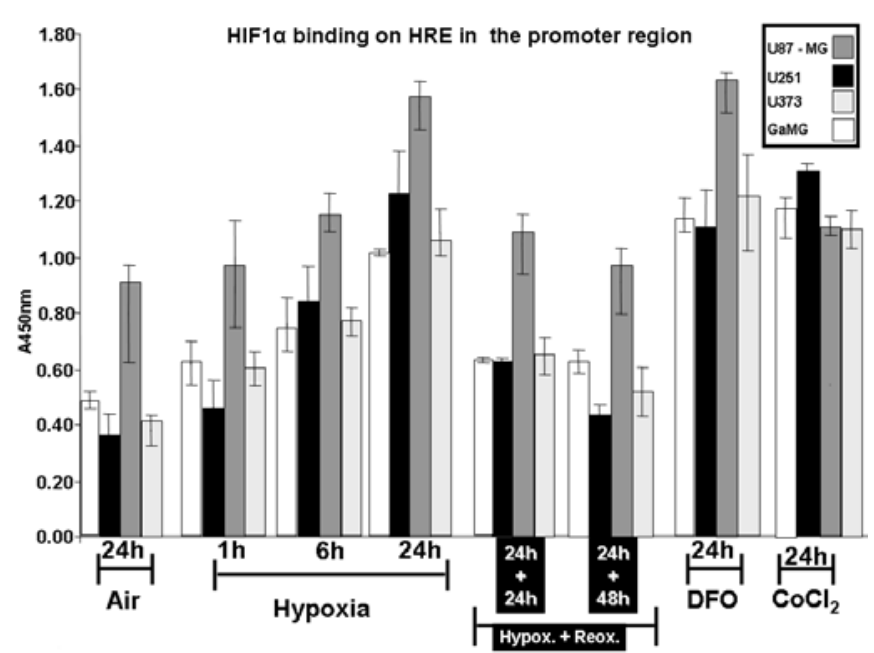

Figure 5. Determination of HIF-1 $\alpha$ binding on the HRE element located within the hypoxia-induced gene promoter region using HRE-binding ELISA.

A physiological MRI approach was considered to completely characterise biopsy-confirmed glioblastoma multiforme (GBM) (40). Tumor hypoxia predicts the likelihood of metastases, tumor recurrence and resistance to chemotherapy and radiation therapy, invasive potential and a decreased patient survival for many human malignancies.

CA-IX and NDRG1 are HIF-1 $\alpha$-regulated genes, which differ in their expression pattern in human glioblastoma. CAIX expression remains relatively stable when the tumor microenvironment is shifted from a hypoxic status to a normoxic one. We show that $48 \mathrm{~h}$ of reoxygenation following $24 \mathrm{~h}$ of extreme hypoxia has only a marginal influence on CA-IX expression. In contrast, NDRG1 expression was not stable to the same degree upon reoxygenation. A combination of hypoxia markers, as is the combination of CA-IX and
NDRG1 in our case, offer the opportunity to measure changes in tumor oxygenation. Such alterations may be relevant to predicting the response of the tumor to radioactive, chemotherapeutic or combinations of such treatment approaches. The half-life of CA-IX was sufficiently long that, once formed, it remained for days even in the absence of continued HIF- $1 \alpha$ expression. HIF- $1 \alpha$ and its regulated genes are induced upon a 'hypoxic shift' of the tumor microenvironment and their expression is usually decreased again upon reoxygenation. However, certain proteins such as CA-IX still showed a substantial expression rate (41-48).

These results have implications for the use of HIF-1 $\alpha$ and its regulated genes as indicators for tumor hypoxia and aggressiveness as well as for the development of hypoxiadirected anti-tumor therapies based on the expression of these proteins.

By using flow cytometry we were able to accurately discriminate NDRG1- and CA-IX-negative and -positive cells in vitro. The measured percentages of positive cells closely reflected the hypoxic status of the cells. The combined expression analysis of NDRG1 and CA-IX by FACS analysis represents a reliable potential tool for brain tumor cancer diagnosis and can be applied to sort chronically hypoxic cells from glioblastoma tumors. Further extensive screening and expression regulation analysis of other hypoxiaregulated genes in different tumors is required in order to discover more HIF-1 $\alpha$-regulated genes that may be considered as hypoxia markers and used for the definition of human tumor tissue state. Further analysis is necessary to examine whether the expression of these genes appears in a similar pattern in tumor tissues of other human organs in vivo and in cell cultures or animal models of the disease.

From a clinical perspective, glioblastoma, also known as WHO grade 4 astrocytoma, is the most common and aggressive type of primary brain tumor, accounting for $52 \%$ of all primary brain tumor cases and $20 \%$ of all intracranial tumors. GBMs are sporadic, without a familial predilection,
A

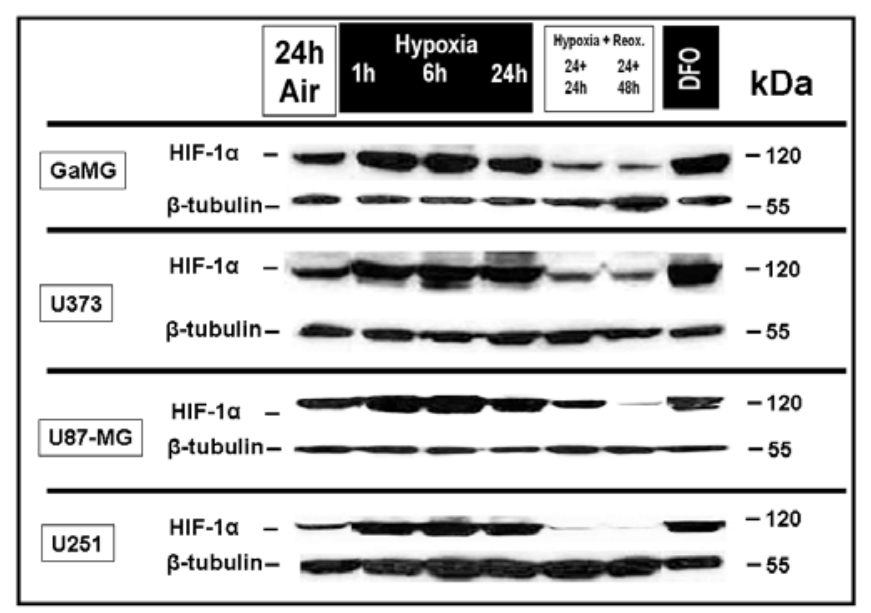

B

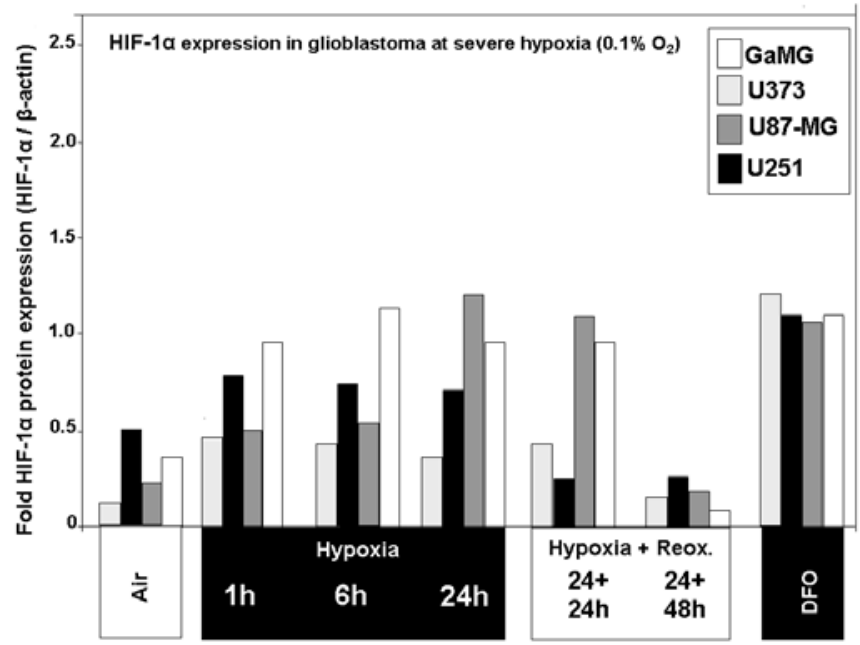

Figure 6. (A) Comparative Western blotting of HIF-1 $\alpha$ protein expression in thenuclear extracts of human malignant glioma cell lines under in vitro hypoxia and after reoxygenation. (B) Densitometric evaluation of HIF-1 $\alpha$ nuclear protein expressed in vitro under hypoxia and reoxygenation conditions. 
although chromosomal aberrations such as PTEN, MDM2 and p53 mutation are commonly found in glioblastoma.

The prognosis for patients with GBM is very low, even with complete surgical tumor resection in combination with radio- and chemotherapeutic means. The five-year survival rate is $<3 \%$. Tumor recurrence after surgery and radiotherapy is almost inevitable. Tumors usually reappear within $2 \mathrm{~cm}$ of the original site, and $10 \%$ of patients develop new lesions at distant sites. Reoperation and/or brachytherapy have been attempted, with uncertain results. The most aggressive therapy, a second surgery together with chemotherapy, is applied in the patient age group of $<40$ years.

HIF- $1 \alpha$-regulated CA-IX and NDRG1 overexpression is induced concomitantly with the development of an hypoxic environment within the tumor. While CA-IX is more chronically expressed, NDRG1 is expressed due to acute hypoxic events within the tumor environment. We showed that the FACS analysis of CA-IX combined with NDRG1 expression give a clear hint about the hypoxic condition of GBM tumor cells. Therefore, our results may extend the analytic identification procedures and time-limited therapeutic options. Therapeutic strategies for the treatment of human astrocytic tumors should consider CA-IX as well as NDRG1 as target molecules for a valid approach in conjunction with tumor hypoxia in the human brain.

\section{Acknowledgements}

This work was supported in part by a grant from the Deutsche Forschungsgemeinschaft (VO 871/2) to DV and by IZKF Würzburg (B25) to $\mathrm{CH}$. We thank Bayer Healthcare Co. for provision of the M75 monoclonal antibody.

\section{References}

1. Elstner A, Holtkamp N and von Deimling A: Involvement of HIF-1 in desferrioxamine-induced invasion of glioblastoma cells. Clin Exp Metastasis 24: 57-66, 2007.

2. Hodges TW, Hossain CF, Kim YP, Zhou YD and Nagle DG: Molecular-targeted antitumor agents: the Saururus cernuus dineolignans manassantin $\mathrm{B}$ and 4-O-demethylmanassantin B are potent inhibitors of hypoxia-activated HIF-1. J Nat Prod 67: 767-771, 2004.

3. Turcotte ML, Parliament M, Franko A and Allalunis-Turner J: Variation in mitochondrial function in hypoxia-sensitive and hypoxia-tolerant human glioma cells. Br J Cancer 86: 619-624, 2002.

4. Secomb TW, Hsu R, Braun RD, et al: Theoretical simulation of oxygen transport to tumors by three-dimensional networks of microvessels. Adv Exp Med Biol 454: 629-634, 1998.

5. Yoshida D, Kim K, Noha M and Teramoto A: Hypoxia inducible factor 1-alpha regulates of platelet derived growth factor-B in human glioblastoma cells. J Neurooncol 76: 13-21, 2006.

6. Semenza GL: Targeting HIF-1 for cancer therapy. Nat Rev Cancer 3: 721-732, 2003.

7. Brown JM and Wilson WR: Exploiting tumour hypoxia in cancer treatment. Nat Rev Cancer 4: 437-447, 2004.

8. Bos R, Zhong H, Hanrahan CF, Mommers EC, Semenza GL, Pinedo HM, Abeloff MD, Simons JW, van Diest PJ and van der Wall E: Levels of hypoxia-inducible factor- $1 \alpha$ during breast carcinogenesis. J Natl Cancer Inst 93: 309-314, 2001.

9. Bos R, van der Groep P, Greijer AE, Shvarts A, Meijer S, Pinedo HM, Semenza GL, van Diest PJ and van der Wall E: Levels of hypoxia-inducible factor- $1 \alpha$ independently predict prognosis in patients with lymph node negative breast carcinoma. Cancer 97: 1573-1581, 2003.

10. Vordermark D, Kaffer A, Riedl S, Katzer A and Flentje M: Characterization of carbonic anhydrase IX (CA IX) as an endogenous marker of chronic hypoxia in live human tumor cells. Int J Radiat Oncol Biol Phys 61: 1197-1207, 2005.
11. Haapasalo JA, Nordfors KM, Hilvo M, Rantala IJ, Soini Y, Parkkila AK, Pastoreková S, Pastorek J, Parkkila SM and Haapasalo HK: Expression of carbonic anhydrase IX in astrocytic tumors predicts poor prognosis. Clin Cancer Res 12: 473-477, 2006.

12. Saarnio J, Parkkila S, Parkkila AK, Haukipuro K, Pastoreková S, Pastorek J, Kairaluoma MI and Karttunen TJ: Immunohistochemical study of colorectal tumors for expression of a novel transmembrane carbonic anhydrase, MN/CA IX, with potential value as a marker of cell proliferation. Am J Pathol 153: 279-285, 1998.

13. Said HM, Staab A, Hagemann C, et al: Distinct patterns of hypoxic expression of carbonic anhydrase IX (CA IX) in human malignant glioma cell lines. J Neurooncol 81: 27-38, 2007.

14. Qu X, Zhai Y, Wei H, et al: Characterization and expression of three novel differentiation-related genes belong to the human NDRG gene family. Mol Cell Biochem 229: 35-44, 2002.

15. Bandyopadhyay S, Pai SK, Gross SC, et al: The Drg-1 gene suppresses tumor metastasis in prostate cancer. Cancer Res 63: 1731-1736, 2003.

16. Piquemal D, Joulia D and Commes T: Transforming growth factor- $\beta 1$ is an autocrine mediator of U937 cell growth arrest and differentiation induced by vitamin D3 and retinoids. Biochim Biophys Acta 1450: 364-373, 1999.

17. van Belzen N, Dinjens WN, Diesveld MP, et al: A novel gene which is up-regulated during colon epithelial cell differentiation and down-regulated in colorectal neoplasms. Lab Invest 77: 85-92, 1997.

18. Angst E, Sibold S, Tiffon C, et al: Cellular differentiation determines the expression of the hypoxia-inducible protein NDRG1 in pancreatic cancer. Br J Cancer 95: 307-313, 2006.

19. Greijer AE, van der Groep P, Kemming D, et al: Up-regulation of gene expression by hypoxia is mediated predominantly by hypoxia-inducible factor 1 (HIF-1). J Pathol 206: 291-304, 2005.

20. Salnikow K, Davidson T, Zhang Q, et al: The involvement of hypoxia-inducible transcription factor-1-dependent pathway in nickel carcinogenesis. Cancer Res 63: 3524-3530, 2003.

21. Cangul H: Hypoxia upregulates the expression of the NDRG1 gene leading to its overexpression in various human cancers BMC Genet 5: 27, 2004.

22. Han YH, Xia L, Song LP, et al: Comparative proteomic analysis of hypoxia-treated and untreated human leukemic U937 cells. Proteomics 6: 3262-3274, 2007.

23. Zhang P, Tchou-Wong KM and Costa M: Egr-1 mediates hypoxia-inducible transcription of the NDRG1 gene through an overlapping Egr-1/Sp1 binding site in the promoter. Cancer Res 67: 9125-9133, 2007.

24. Ellen T, Ke Q, Zhang P and Costa M: NDRG1, a growth and cancer related gene: Regulation of gene expression and function in normal and disease states. Carcinogenesis (In press).

25. Brown JM and Le QT: Tumor hypoxia is important in radiotherapy, but how should we measure it? Int J Radiat Oncol Biol Phys 54: 1299-1301, 2002.

26. Akslen LA, Andersen KJ and Bjerkvig R: Characteristics of human and rat glioma cells grown in a defined medium, Anticancer Res 8: 797-803, 1988.

27. Said HM, Hagemann C, Staab A, Stojic J, Kühnel S, Vince GH, Flentje M, Roosen K and Vordermark D: Expression patterns of the hypoxia-related genes osteopontin, CA9, erythropoietin,VEGF and HIF-1alpha in human glioma in vitro and in vivo. Radiother Oncol 83: 398-405, 2007.

28. Said HM, Hagemann C, Stojic J, et al: GAPDH is not regulated in human glioblastoma under hypoxic conditions. BMC Mol Biol 8: 55, 2007.

29. Coleman CN, Mitchell JB and Camphausen K: Tumor hypoxia: chicken, egg, or a piece of the farm? J Clin Oncol 20: 610-615, 2002.

30. Gao W, Ferguson G, Connell P, Walshe T, Murphy R, Birney YA, O'Brien $\mathrm{C}$ and Cahill PA: High glucose concentrations alter hypoxia-induced control of vascular smooth muscle cell growth via a HIF-1alpha-dependent pathway. J Mol Cell Cardiol 42: 609-619, 2007.

31. Vordermark D, Menke DR and Brown JM: Similar radiation sensitivities of acutely and chronically hypoxic cells in HT 1080 fibrosarcoma xenografts. Radiat Res 159: 94-101, 2003.

32. Dooley S, Said HM, Gressner AM, et al: Y-box protein-1 is the crucial mediator of antifibrotic interferon-gamma effects. J Biol Chem 281: 1784-1795, 2006.

33. Said HM, Katzer A, Flentje M, et al: Response of the plasma hypoxia marker osteopontin to in vitro hypoxia in human tumor cells. Radiother Oncol 76: 200-205, 2005. 
34. Collingridge DR, Piepmaier JM, Rockwell S and Knisely JP: Polarographic measurements of oxygen tension in human glioma and surrounding peritumoural brain tissue. Radiother Oncol 53: 127-131, 1999.

35. Evans SM, Judy KD, Dunphy I, Jenkins WT, Hwang WT, Nelson PT, Lustig RA, Jenkins K, Magarelli DP, Hahn SM, Collins RA, Grady MS and Koch CJ: Hypoxia is important in the biology and aggression of human glial brain tumors. Clin Cancer Res 10: 8177-8184, 2004.

36. Koukourakis MI, Giatromanolaki A, Sivridis E, et al: Hypoxiaregulated carbonic anhydrase-9 (CA9) relates to poor vascularization and resistance of squamous cell head and neck cancer to chemoradiotherapy. Clin Cancer Res 7: 3399-3403, 2001.

37. Rich JN: Cancer stem cells in radiation resistance. Cancer Res 67: 8980-8984, 2007.

38. DeHaan C, Habibi-Nazhad B, Yan E, Salloum N, Parliament M and Allalunis-Turner J: Mutation in mitochondrial complex I ND6 subunit is associated with defective response to hypoxia in human glioma cells. Mol Cancer 3: 19, 2004.

39. Ragel BT, Couldwell WT, Gillespie DL and Jensen RL: Identification of hypoxia-induced genes in a malignant glioma cell line (U-251) by cDNA microarray analysis. Neurosurg Rev 30: 181-187, 2007.

40. McMillan KM, Rogers BP, Field AS, Laird AR, Fine JP and Meyerand ME: Physiologic characterisation of glioblastoma multiforme using MRI-based hypoxia mapping, chemical shift imaging, perfusion and diffusion maps. J Clin Neurosci 13: 811-817, 2006.

41. Kaluz S, Kaluzova M and Stanbridge EJ: Expression of the hypoxia marker carbonic anhydrase IX is critically dependent on SP1 activity. Identification of a novel type of hypoxiaresponsive enhancer. Cancer Res 63: 917-922, 2003.
42. Rafajova M, Zatovicova M, Kettmann R, Pastorek J and Pastoreková S: Induction by hypoxia combined with low glucose or low bicarbonate and high posttranslational stability upon reoxygenation contribute to carbonic anhydrase IX expression in cancer cells. Int J Oncol 24: 995-1004, 2004

43. Olive PL, Vikse C and Trotter MJ: Measurement of oxygen diffusion distance. Measurement of oxygen diffusion distance in tumor cubes using a fluorescent hypoxia probe. Int J Radiat Oncol Biol Phys 22: 397-402, 1992.

44. Maxwell PH, Wiesener MS, Chang GW, Clifford SC, Vaux EC, Cockman ME, Wykoff CC, Pugh CW, Maher ER and Ratcliffe PJ: The tumour suppressor protein VHL targets hypoxia inducible factors for oxygen-dependent proteolysis. Nature 399: 271-275, 1999.

45. Pastoreková S and Pastorek J: In: Carbonic Anhydrase. Its Inhibitors and Activators. Supuran CT, Scozzafava A and Conway J (eds). CRC, Boca Raton, pp255-281, 2004.

46. Semenza GL: Hypoxia and cancer. Cancer Metastasis Rev 26: 223-224, 2007.

47. Brahimi-Horn MC and Pouyssegur J: Oxygen, a source of life and stress. FEBS Lett 581: 3582-3591, 2007.

48. Yunokawa M, Tanimoto K, Nakamura H, Nagai N, Kudo Y, Kawamoto T, Kato Y, Hiyama E, Hiyama K and Nishiyama M: Differential regulation of DEC2 among hypoxia-inducible genes in endometrial carcinomas. Oncol Rep 17: 871-878, 2007. 